\title{
Desafios para um novo pacto sanitário: biotecnologia e risco
}

\section{Challenges for a new health pact: biotechnology and risk}

Aurea M aria Zöllner Ianni ${ }^{1}$

Abstract This article discusses the use and the incorporation of biotechnological practices in Public Health, in a risk society context. Considering the contemporary social theoreticians, the implications of the bi otechnological uses have been analyzed. The article was divided into three different parts. In the first part, the examples of biological manipulation are presented, developed in the health scope and the consequences of using the techniques on the ecological dynamic of the populations involved on it. Then it presents what these biological modified hybrid species are, and how their incorporation on the common practices of Public Health occurs. The second part presents the theoretical references, which are used to the analysis that situates the contemporary society in the reflexive stage of modernization and has its form in the risk society. The third and last part of the article argues the biotechnological uses on health, specifically on Public $\mathrm{H}$ ealth, tackling the risk aspects of its application, showing that another sanitary pact is needed.

Key words Biotechnology, Publichealth, H ybrids, Social sciences, Nature sciences, Risk society
Resumo Este artigo discute a incorporação e o uso da biotecnologia na Saúde Pública, no contexto da sociedade de risco. Tendo por referência autores da teoria social contemporânea, analisam-se as implicações das práticas biotecnológicas. 0 artigo está dividido em três partes. Na primeira, são apresentados alguns exemplos de manipulação biológica desenvolvidos no âmbito da saúde e as consequências da utilização dessas técnicas na dinâmica ecológica das populações envolvidas. A partir desses exemplos, discute-se 0 que vem a ser esses seres biologicamente modificados, híbridos, e como ocorre sua incorporação nas práticas sociais, especialmente as de Saúde Pública. A segunda parte apresenta o referencial teórico utilizado para análise, que situa a sociedade contemporânea na etapa reflexiva da modernização e que tem na sociedade de risco uma de suas configurações. A última parte do artigo problematiza os usos da biotecnologia em saúde, mais especificamenteem SaúdePública, abordando os aspectos de risco dessa aplicação, propondo o necessário debate sobre um outro pacto sanitário. Palavras-chave Biotecnologia, Saúde pública, H íbridos, Ciências sociais, Ciências naturais, Sociedade de risco

${ }^{1}$ Universidade de São Paulo. Av. Dr. Arnaldo 715, Cerqueira Cesar. 01246-904 São Paulo SP. aureanni@isaude.sp.gov.br 


\section{O problema}

A Saúde vem enfrentando há décadas, ecrescentemente, o problema do aumento das doenças, tanto no que se refere à etiologia das mesmas, quanto à extensão populacional e sua gravidade. É o que se convencionou denominar de emergência, reemergência e recrudescência das doenças' ${ }^{1} 0$ debate sobre este fenômeno se dá em diferentes direções; desde a necessária investigação científica eseu desenvolvimento tecnológico, com o propósito de "descobrir" as causas e mecanismos de intervenção, até estratégias de reestruturação dos modelos assistenciais, dos sistemas de serviços e das políticas públicas de proteção, prevenção e promoção à saúde. Entretanto, pode-se dizer, concordando com Berlinguer", que "o inimigo não está parado, mas em contínua mobilidade". E é esta mobilidade que provoca grande inquietação nos mais atentos e intrigados atores desse debate. Apesar dos avanços incalculáveis no conhecimento técnico-científico, na descoberta das causas sociais que condicionam e determinam os quadros nosológicos, no conhecimento sobre a etiologia das doenças e nas estratégicas públicas das políticas de saúde, as populações encontram-se cada vez mais expostas a diferentes doenças.

É claro queo avanço das pesquisas científicas e do desenvolvimento tecnológico, a miscigenação de povos e raças, o contato humano com animais, a circulação e ingestão de víveres e alimentos, a migração internacional das populações, a invasão de nichos ecológicos, etc., constituem causas suficientes para explicar tanto a emergência (ou descoberta) de novas doenças quanto a intensa produção técnico-científica voltada para a cura ou proteção das mesmas. M as, apesar desses avanços, o quefaz com queas doenças permaneçam, redefinam-se, reapareçam?

Há uma ecologia das doenças ${ }^{3-5}$ que as faz sobreviver, morrer, aparecer novamente, transformar-se, reinventar-se, permanecer latentes ou não. Essa ecologia nos remete ao ciclo vital dessas entidades mórbidas, ao ciclo vital dos vetores e hospedeiros, aos outros meios de veiculação, ao ciclo vital dos organismos e populações, ao meio, ao ecossistema, aos determinantes socioambientais, enfim. Remete, portanto, ao que se compreende por natural e social, biológico e social e ao que se pressupõe sejam, hoje, as coisas da natureza e as da sociedade, e suas relações.

A fim de esclarecer, mais exatamente, do que se pretende tratar neste artigo, serão utilizados três exemplos amplamente conhecidos na Saúde.
0 primeiro é o caso da doença da "vaca louca", encefalopatia espongiforme bovina ${ }^{6}$. 0 agenteinfeccioso dessa doençaéo príon, entidadedescoberta em 1980 emenor que o vírus. É formado de proteína e tem capacidade para se reproduzir no tecido do sistema nervoso central dos animais, os seres humanos aí incluídos. A presenta mecanismos de reprodução e infecção, ainda inteiramente desconhecidos. Uma doença que acometia animais e transferiu-se ao homem, pelo próprio homem, através da introdução de proteína animal dada ao gado para engorda; alimento que jamais integrara o cardápio bovino, já que este é originariamente uma espécie herbívora. As proteínas animais, ingeridas pelos rebanhos bovinos, possibilitaram a transferência do príon ao gado de corte, penetrando, desta forma, na cadeia alimentar humana. Desenvolveu-se, assim, um problema de segurança ecológica eal imentar, produzido e desenvolvido pela ação antropogênica.

0 segundo exemplo se refere à incompetência para controlar e/ou destruir bactérias, apesar das inúmeras gerações de antibióticos. Os inúmeros mecanismos pelos quais as bactérias se tornam resistentes, equeconsistem de mutações aleatórias, demonstram a alta complexidade desses organismos e consistem em: (a) produção de substâncias químicas que se ligam ao antibiótico causando sua destruição; (b) modificação da parede celular, não deixando 0 antibiótico entrar; (c) não produzir componentes de suas cé lulas, o que abre brechas para o "ataque" do antibiótico. Recentemente, novas pesquisas observaram, ainda, que as bactérias hiper-resistentes chegam a se tornar reservatórios genéticos de mecanismos de resistência aos antibióticos. Estabelece-se, desta forma, uma corrida antibióticos-bactérias, que se tornou um grave problema deSaúdePública, consideradas as resistências em âmbito hospitalar ${ }^{7-9}$. E esse mecanismo de produção de resistência ocorre, também, em outros microorganismos, os vírus e fungos.

0 último exemplo é o de uma pesquisa desenvolvida na Universidade John Hopkins, nos Estados Unidos, com participação de pesquisadores brasilei ros da FSP/USP, sobre os mecanismos de controle da malária. Pesquisas laboratoriais desenvolveram mosquitos modificados por engenharia genética, resistentes ao parasito, que conseguem semultiplicar mais rapidamente que 0 inseto "selvagem", transmissor da doença. A estratégia de saúde pública, decorrente desta"invenção", seria espalhar no meio ambiente, no habitat, esses mosquitos transgênicos. M arcelo Jacobs-Lorena ${ }^{10}$, líder do grupo de pesquisa, fala 
sobre dois aspectos desse trabalho: o científico e o ético. Q uanto ao científico, ele diz que os resultados demonstraram que os mosquitos transgênicos têm uma vantagem quando eles se alimentam com sangue infectado, mas pensamos que essa vantagem não seja de magnitude suficiente para queo geneseespal hepela população dos mosquitos no campo [grifo nosso]. Quanto ao ético, afirma: "precisamos trabalhar com a população que seria afetada pela soltura de mosquitos transgê nicos e com governos, para assegurá-los de que não haja riscos secundáriossignificativos" [ grifo nosso]. Mais adiante, sobre possíveis críticas de ambientalistas sobre a introdução desses seres transgênicos - os mosquitos - no ambiente, 0 pesquisador diz: "uma vantagem que temos em relação à soja é que tentamos salvar vidas, enquanto plantas transgênicas visam somente vantagem financeira" [grifo nosso]. Este debate ganha contornos extremamente complexos se enriquecido com a referência de Jarbas Barbosa, ex-quadro do M inistério da Saúde, Brasil, e atual diretor da Área de Vigilância em Saúde eControle de D oenças da O rganização Pan-Americana de Saúde (OPAS), sobre o fracasso da erradicação da dengue, em que elealerta sobrea necessidade de usar o "conceito correto - que não se pode acabar com o mosquito" ${ }^{11}$. Isto sugere que mosquitos transgênicos poderão, também eles, quando soltos no meio ambiente, atingir uma reprodução e transmutações bem diferentes daquelas encontradas em ambiente laboratorial.

Garret ${ }^{12}$ afirma que pouco se sabe das diferenças entre estudar seres vivos nos tubos de ensaio e estudá-los em animais ou seres humanos infectados. Pouco se sabe, também, dessas relações nos ambientes. Este é um percurso em que muito podeacontecer. É uma enorme caixa-preta os modos pelos quais acontecem as transmissões microbianas, os artifícios para enganar o sistema imunológico onde são instalados os germes, os cruzamentos das espécies, as mutações, as mudanças de genes, as inúmeras interaçõ̃es competitivas e coevolutivas entre comunidades, o ritmo e grau da seletividade. Vários cientistas admitem que, nessa caixa-preta, o segredo étão grandeque se torna quase impossível avaliarem-se todos os riscos do surgimento de um ser patogênico, o que torna esse tipo de experimento um ato acompanhado sempre de grande incerteza e risco.

Os exemplos utilizados apresentam aspectos comuns: todos eles guardam alto grau deimprevisibilidade, de incontrolabilidade e de insegurança. Apresentam, também, outra característica comum, a de ter como causas fatores artifici- ais, isto é, "fatores não preexistentes na natureza, mas criados, estimulados ou reforçados por intervenção do homem, tornando-se, por isso, doenças não fisiógenas, mas sim antropógenas"2. Dizem respeito a uma etapa do desenvolvimento da sociedade em que os processos já não transcorrem dentro dos marcos de uma natureza intocada, inanimada, mas sim a uma etapa da modernidade em que a natureza encontra-se totalmente manufaturada, onde a biotecnologia, expressão dessa natureza socialmente produzida, impera, inaugurando uma era de seres híbridos, mistos de natureza e cultura.

Este processo social coloca à Saúde Pública inúmeras questões, não apenas no que se refereà produção de novos conhecimentos e práticas, mas também no que se refere a um debate propriamente interno, intrínseco ao campo, já que este se constitui num vasto complexo produtivo biotecnológico (pesquisa técnico-científica, produção, distribuição e consumo) ${ }^{13}$.

A Saúde Pública/Coletivaé, no atual contexto de desenvolvimento técnico-científico, uma importante esfera social de produção de híbridose riscos. A Saúde Pública catalisa híbridos e riscos.

\section{Os híbridos}

Os híbridos são objetos mistos de natureza e cultura constituídos pelas práticas sociais, e que re sultam em "seres", "objetos" ou "coisas", completamentenovos. Para Latour ${ }^{14}$, as construções desses objetos, fatos, ou artefatos - ainda que sociais -, estão tão impregnadas de outros processos e objetos naturais que não podem mais ser caracterizadas apenas por uma ou outra dinâmica, um ou outro determinante - social ou natural.

Os fatos técnico-científicos, as descobertas, ainda que construídos socialmente, não podem ser reduzidos ao social por que estão povoados de objetos da natureza, mobilizados para construí-los. Há o exemplo do buraco da camada de ozônio na atmosfera que, segundo o autor, é por demais social para ser natural. Na Saúde, no Brasil, pode-seutilizar o exemplo do vírus da poliomielite - vivo, porém atenuado -, que depois de décadas de campanhas de vacinaçãa ${ }^{15}$, está de tal forma disseminado nos ambientes e populações que poderíamos questionar sobre a sua real dimensão natural ou artificial. Outros fenômenos da Saúde podem ser invocados, como as neoplasias, por exemplo, por demais sociais (lembre mo-nos dos hábitos, estilos de vida, exposição a substâncias e produtos em ambientes de traba- 
Iho, contaminação deriosemananciais, etc.) para serem naturais, e por demais naturais (alguns cânceres são considerados de etiologia infecciosa) para serem sociais.

O campo da Saúde é, portanto, povoado de mistos de natureza e cultura, híbridos. E o híbrido não é uma novidade. Ele surge com a época moderna: A modernidade é muitas vezes definida através do humanismo, seja para saudar o nascimento do homem, seja para anunciar sua morte. M as o próprio hábito é moderno, uma vez que este continua sendo assi métrico. Esquece o nascimento conjunto da "não-humanidade" das coisas, dos objetos ou das bestas [... $]^{14}$.

Por não ser fenômeno tão recente, outros autores também já referiram à emergência dessefato moderno; são interpretações deste mesmo fenômeno, ainda que em outros termos. Há uma "dupla linguagem", que mobiliza a natureza no seio das relações sociais, ao mesmo tempo em que a mantêm infinitamente distantedos homens. Esta construção moderna, de mobilização e, simultaneamente, de coisificação da natureza, deixa 0 mundo humano livre para construir e desconstruir a sociedade, tornando suas leis inevitáveis, necessárias e absolutas. Assim são produzidas as leis sobrea natureza, ou seja, em linguagem sobre um natural que paradoxalmente oculta. I sto aparece com muita argúcia nos trabalhos de Keith Thomas. Em seu livro $\mathrm{O} \mathrm{H}$ omem e M undo $\mathrm{N}$ atu$\mathrm{ral}^{16}, \mathrm{o}$ autor apresenta um estudo etno-historiográfico que pode ser lido à luz dos híbridos. Se assim for feito, pode-se afirmar que a trajetória dos homens, dos séculos XVI ao XIX, é uma história de constituição de seres híbridos. Ancoradasna legitimação classificatória deordem científica, e também religiosa, as camadas dominantes foram estabelecendo classes de homens mais ou menos bestiais, selvagens, brutos, desalmados, ferozes, ignorantes, sem religião, sensuais: os índios, os bebês, as mulheres, os pobres, os loucos, os vagabundos, os mendigos e outros, num ato de purificação do branco, abastado, limpo, católico, culto. Essa mediação só foi possível pela persistente construção de um outro, de outra natureza: o índio, o selvagem, o desalmado, a bruxa, o negro, o inculto, o pagão, etc.

A construção da idéia de Homem é a construção de comparações dos atributos de homens e animais, com base na linguagem inteligível, no conhecimento, nas técnicas e, também, na religião cristã̃ ${ }^{16}$. A modernidade pode ser vista, portanto enesse sentido, como a construção de um discurso sobre oshíbridosque, em verdade, constituem-na amplamente. 0 uso dos termos selva- gem eatenuado para o vírus da poliomielite, por exemplo, ressoa, em larga medida, essa legitimação classificatória, secularmente construída.

Segundo Latour ${ }^{14}$, o hibridismo ocorre por meio de uma dupla constituição a fim de que natureza esociedadepermaneçam absolutamente distintas: 0 trabal ho de purificação, por um lado, e o de tradução, do outro. Os fatos secularizados, produzidos pelas sociedades e representados num Estado para além dos homens, essa é a purificação; simultaneamente, há uma constante e intensa mobilização de coi sas diversas einumeráveis da natureza, para a construção e consistência humana; éa tradução. Assegura-se, dessa forma, a não humanidade da natureza (que se torna simples objeto de apropriação) e a humanidade do social. Há uma separação entreo mundo natural - construído pelo homem -, e o mundo social - sustentado pelas coisas da natureza. Esses mundos aparecem como opostos, divorciados, ainda que sejam mutuamente reflexivos, reciprocamentedeterminantes esignificantes.

$\mathrm{Na}$ etapa biotecnológica da sociedade moderna, entretanto, essefenômeno assumedimensões jamais vistas. A técnica, que transforma se res vivos, avança rapidamente sobre o mundo das coisas, misturando, cruzando e amalgamando seres e objetos, numa reunião única de diferentes, diversos e opostos, colonizando (toda) a natureza.

$\mathrm{Na}$ trajetória de diferenciar-se das coisas do mundo natural, a ação geomórfica humana não conhece limites. Para M oscovici ${ }^{17}$, aquilo que em outras épocas foi uma utopia - o poder humano sobre a natureza -, transforma-se, na etapa contemporânea da modernidade, numa "ordem natural em expansão"; uma violência, quecomporta riscos incal culáveis equese desdobra para além da apropriação dos bens dos outros, fazendo avançar o domínio sobre a natureza. Não se limitando apenas em extirpar, ou extrair, as coisas da natureza para sua sobrevivência e acumulação de bens, a sociedade humana passa a modificá-la; fauna e flora são alteradas, privando as espécies de reprodução. É nesse sentido que o social passa a ser engendrado pelo social e não mais pelo não-social. Por isso a história, nesta fase da modernidade, éo quese podedenominar de história humana da natureza. É a etapa reflexiva da modernidade, isto é, aquela em que a sociedade se confronta com os efeitos/resultados do seu próprio desenvolvimento (econômico, científico, político, cultural, etc.).

A discussão sobre o caráter invasivo das modernas tecnologias nos corpos humanos enos 
ambientes é, em larga medida, desdobramento dessa problemática, e recorrente no desenvolvimento da sociedade. Processos naturais, ao Iongo da história humana, têm sido, cada vez maise crescentemente, tecnológicos. “O homem éaúnica espécieanimal capaz de inventar ede criar seu ambiente de vida, e que em tal reinvenção do ambiente o homem modifica a si mesmo" ${ }^{2}$.

Neste contexto, as práticas biotecnológicas expressam exemplarmente 0 paradoxo moderno sociedade/natureza. Emerge uma biossociedade em que a natureza é moldada na cultura, é compreendida como prática social ${ }^{18}$. N esta sociedade, a natureza pode ser conhecida, produzida e refeita pela técnica, tornando-se, finalmente, artificial, assim como a cultura é natural. 0 "social", enquanto categoria típica da Ciência Social do século XIX ${ }^{19}$, se dissolve.

Duclos ${ }^{20}$ vai um pouco além. Diz queaforma atual da necessária separação cultura-natureza, ou sociedade-natureza, assume seu mito de separação entre dois humanos: um, como cultura, e o outro, como tecnonatureza. Como ordem natural em expansão, o capitalismo, na fase contemporânea, transforma-se num manancial de reservas naturais, agora não mais constituídas apenas de força de trabalho, de meios de produção potenciais, mas de recursos naturais preservados ou potencialmente recicláveis, além da exploração das coisas da natureza recriadas.

N este cenário, a evolução das espécies, a sua sobrevivência ediversificação, têm queser repensadas; agora como processos não apenas "biológicos", mas naturalmente culturais. E considerando a história evolutiva das espécies, o grande impacto, nos dias dehoje, diz respeito à escala eà dimensão em quea técnica invadiu a vida, criando e eliminando vidas, organismos, populações. "A civilização tecnicista, além dos prodigiosos meios de difusão de que dispõe, é, neste sentido, totalitária", diz Friedmann ${ }^{21}$.

Este é o contexto em que os híbridos são, cada vez mais, produzidos e reproduzidos pelas/ nas práticas biotecnológicas. A Saúde, campo produtor e disseminador desses seres, fatos ou coisas, desempenha papel protagonista neste cenário, já que, como a agricultura, éuma área que catalisa não apenas a produção, como também a distribuição e o consumo desses objetos, mistos de natureza e cultura, essas "novas" espécies.

\section{Aspráticas biotecnológicas} na sociedade de risco

Estas questões ganham extrema relevância no contexto contemporâneo caracterizado como a etapa reflexiva da modernização, eque se desdobra na sociedade de risco. Neste momento, o projeto da sociedade industrial entra em sua etapa autodestrutiva, quer dizer, o êxito das modernizações já não transcorre dentro das vias e categorias da sociedade, mas sim contra elas. Entra em colapso a idéia de controle, de certeza e de segurança.

Trata-se de um novo estágio da sociedade, em que 0 progresso pode se transformar em autodestruição, em queum tipo demodernização destrói o outro e o modifica; é a autoconfrontação.

"'M odernização reflexiva' significa a possi bilidade deuma (auto)destruição criativa para toda uma era: aquela da sociedadeindustrial. 0 'sujeito' dessa destruição criativa não é a revolução, não éa crise, mas a vitória da modernização ocidental"22.

As grandes correntes da teoria social, constituídas a partir do século XIX ${ }^{19}$, sempre atribuíram à crise - econômica ou política - a superação do capitalismo, ou o declínio dessa etapa da modernidade. 0 que a teoria da modernização reflexiva diz é que não é a crise do capitalismo que produz essa nova forma social, mas, ao contrário, são as suas vitórias. No caso da Saúde, podemos exemplificar essefenômeno social com a iatrogenia, largamentediscutida por Illich ${ }^{23}$, um de seus mais contumazes críticos. Trata-se de uma "epidemia" de malefícios provocados pelas intervenções médico-sanitárias, decorrentes dos próprios avanços do desenvolvimento do conhecimento científico-tecnológico do campo da saúde (indústria médico-farmacêutica, tecnologias diagnósticas e terapêuticas, equipamentos hospitalares, etc.). Grmek ${ }^{3}$, mais recentemente, traz outro exemplo. Atribui à expansão da epidemia de aids o uso inadequado da tecnologia médica e dos procedimentos em saúde; a falta de controle dos bancos de sangue e das práticas de transfusão, em especial, mas também ao intenso uso de procedimentos invasivos.

Neste sentido, o processo revolucionário da luta de classes, por exemplo, como propuseram os pensadores sociais inspirados na Revolução Burguesa, não constituem, na atualidade, o fator desencadeante da dissolução dos contornos da sociedade, mas, sim, a modernização normal e a adicional. Ou seja, a incorporação gradual e extensiva de mais desenvolvimento, mais tecnolo- 
gia. É o caso dos riscos concretos e potenciais desencadeados pelas mudanças climáticas globais, queprovocam alterações em diferentes regiões do planeta, atingindo, indistintamente, ricos e pobres (ainda que menos protegidos socialmente, sem dúvida), países do primeiro ou segundo mundo, os desenvolvidos e em desenvolvimento. $M$ as nenhuma imagem chega a capturar o mundo da alta modernidade, que é muito mais aberto e contingente do que sugere qualquer uma dessas imagens, e isso acontece exatamente por causa - e não apesar - do conhecimento que acumulamos sobre nós mesmos e sobre 0 ambiente material. É um mundo em quea oportunidade e o perigo estão equilibrados em igual medida, diz Beck ${ }^{22}$.

Desta forma, Ulrich Beck ${ }^{24}$ introduz um outro componente à reflexividade da modernidade; este elemento é o risco. Para o autor, a sociedade atual é também sociedade de risco, uma sociedade que põe em risco a si mesma.

A modernidade, que parecia trazer crescente informação sobre os mundos natural e social e, com isso, um controle cada vez maior sobre esses mundos, não se confirmou. Por isso a modernização é reflexiva, o que quer dizer que os efeitos produzidos pela sociedade já não podem mais ser tratados e assimilados no sistema da sociedade industrial: é a autoconfrontação.

A autoconfrontação éa radicalização da modernidade. Essa radicalização corrói as premissas da sociedade industrial e invade seus contornos. E essa mudança da sociedade industrial vem ocorrendo subrrepticiamente, sem o planejamento de uma nova ordem normal, autônoma, inalterada. Pequenas medidas assumem grandes efeitos cumulativos, num processo que ocorre, frequentemente, silenciosamente. A sociedade se torna um tema e um problema para ela mesma.

Por isso Ulrick Beck diz que, neste contexto, 0 "outro lado dessa obsolescência é a emergência da sociedade de risco" 22 , já que o motor dessa modernização não éo conhecimento, mas o nãoconhecimento, não éo previsível maso imprevisível, não é a segurança mas a insegurança, a ambivalência, também.

Risco éo enfoquemoderno da previsão econtrole das consequências futuras das ações humanas, das diversas consequências indesejáveis da modernidade. I mportante neste conceito équeo dano possível pode ser contingente, isto é, evitável. 0 conceito de risco éum intento de colonizar o futuro ${ }^{22,25}$.

$\mathrm{N}$ a etapa reflexiva da modernização, essa coIonização do futuro se presentifica, instaurada por meio de práticas produtivas, comunicativas, técnico-administrativas e científicas da sociedade. 0 risco, generalizado e expandido, ésimultaneamente probabilidade e realidade. Em outras palavras: a construção do risco é uma prática de construção de incertezas muito particulares, que podem vir a ter profundas consequências para a vida em sentido mais amplo. A essência do risco não éo que está ocorrendo, mas o que pode vir a ocorrer ${ }^{26}$.

Os riscos são necessariamente construídos; não apenas através das práticas técnico-científicas e produtivas mas, também, por meio da construção cultural da percepção e sensibilidade sobre os potenciais danos, perigos, ameaças.

Como os riscos estão articulados aos processos sociais de toda ordem, eles não se manifestam de forma restrita, limitada; são gerais, planetários, globais. As teorias, os instrumentos e as medidas até então utilizados para avaliar e controlar os riscos, tornam-se, por isso mesmo e cada vez mais, superados e obsoletos.

M uitas vezes, o que causa uma catástrofe não é um erro singular, mas os sistemas que transformam a humanidade desse erro em forças destrutivas, incompreensíveis. N esse sentido, remeter-se a instrumentos de medidas, teorias, etc. para avaliar os perigos, implica trabalhar não apenas com o objetivo, pal pável, concreto, mas sobretudo com o incerto, imprevisível, incontrolável, com o não-saber.

Diferentes trabal hos contribuem para a compreensão deste processo no âmbito da Saúde. Analisando a construção do conceito de risco epidemiológico, eles vão revelando como a epidemiologia migrou, gradativamente, da preocupação com a etiologia das doenças e suas condições de manifestação coletiva, para a preocupação com a investi gação causal em torno de associações; um fator associado a um efeito. 0 cálculo de risco consolida-se, assim, como elemento conceitual nuclear nos estudos de associação $0^{27,28}$. Essa dimensão metodológica - o risco epidemiológico -, que será crescentemente incorporada à pesquisa médica, acaba por definir estilos de vida, produzindo significados que orientam o comportamento dos indivíduos e populações. 0 risco epidemiológico, antes instrumento essencial para identificar a tendência de adoecimento, transforma-seem elemento constitutivo das práticas dos indivíduos e sociedades, da preven ção à intervenção.

É a epidemiologia que informa sobre quais são os fatores de risco: a comida gordurosa, as tentações ricas em colesterol, a fumaça de cigarro. Portanto, é ela que diz quais são as portas que devem 
ser obstruídas à entrada da morte. A medicina, apoiada pelo método epidemi ológico, éo alquimista que possui a pedra filosofal. Ela sustenta possuir o poder de transformar a incerteza em auto-segurança, éa autoridade que aprova (ou desaprova) a forma como cada indivíduo deve viver, uma forma que constantemente derrete e se transforma em novas formas igualmente líquidas, transitórias ${ }^{28}$.

Como os riscos são residuais ${ }^{29}$ ou, dito de outra forma, produzem e reproduzem efeitos colaterais, funda-se uma ambiguidade: a proteção diminui na medida em que aumenta o perigo. Os riscos tornam-se, paulatinamente, mais imprevisíveis, imperceptíveis, incalculáveis, rompendo as fronteiras de tempo-espaço, do específico-inespecífico, do tolerável-intolerável, da normalidade-anormalidade.

Outro aspecto importante da sociedade de risco é que os conflitos da distribuição de recursos e bens produzidos pela sociedade em sua etapa industrial moderna, como os salários, os empregos e o seguro social, por exemplo, são acrescidos dos conflitos criados pelos "mal efícios", emergindo o que Beck vai denominar de conflitos de responsabilidade distributiva22.

Como a construção dos riscos na sociedade industrial é produzida pela sua factibilidade técnica, estessetornam infinitamentereprodutíveis, estendendo-se por cadeias de produção (industrial e de serviços), ecológicas, sistêmicas. A pluralização imanente dos riscos, intrínseca à própria dinâmica (re)produtiva da sociedade industrial, coloca em xeque a racionalidade dos cál culos de risco.

O cál culo de risco é uma forma de calcular o perigo. Entretanto, na atual etapa da modernidade, os riscos vão se tornando incalculáveis, já que estão sendo sistematicamente produzidos de forma imperceptível. 0 exemplo da doença da vaca louca, que ilustra claramente este fenômeno, já foi referido. Asdificuldadesencontradasnasações de controle da vigilância sanitária constituem outro exemplo ilustrativo dessa rede sistêmica de produção imprevisível e reprodutível de riscos. Há casos em que o controle inicial é feito e aprovado segundo as normas de segurança, resultando, ao final da cadeia produção-consumo, em perigo; porque os riscos distribuem-se sistemicamente, podendo aparecer em qualquer momento do fluxo produtivo, tecnológico. Isto faz com que, em muitos casos, se acabe por não localizar 0 ponto exato em que o mal efício emergiu.

N este contexto, os híbridos, ou seja, os seres mistos de natureza e cultura, biotecnológicos, merecem nossa atenção na medida em que cons- tituem objeto fundamental dessa cadeia ecológica, produtiva; se a "externalidade" da natureza podia ser invocada nos tempos pré-modernos, ou nos primórdios da modernidade, agora é impossível. Na etapa industrial tardia, não apenas o ambiente, mas os corpos dos indivíduos e seus processos fisiológicos têm sido cada vez mais invadidos, o que faz com que as práticas biotecnológicas se tornem, gradativamente e cada vez mais, objeto de problematização.

Beck $^{22}$ afirma que há dois aspectos que podem ser distinguidos na dinâmica da sociedade global. 0 primeiro deles é o estágio em que os efeitos e autoameaças são sistematicamente produzidos pela sociedade, mas não se tornam questões públicas ou o centro dos conflitos políticos. O segundo aspecto diz respeito a uma situação completamente diferente, senão oposta; aquela em que os perigos começam dominar os debates e conflitos públicos, tanto na esfera política mais geral quanto na esfera das vidas privadas. A sociedade, nos dias de hoje, convive com essas duas dinâmicas, nessa dupla racionalidade.

Entretanto, o crescimento e a expansão das ameaças produzidas pela sociedade industrial trazem consigo a questão da autolimitação e da necessária negociação política dos limites desse desenvolvimento, dessa racionalidade, a fim de instituir dinâmicas sociais que possibilitem traçar limites entre os danos e que criem as condições favoráveis para responder questões como: (1) qual é a capacidade de suporte, das populações e dos ecossistemas, para suportar os perigos impingidospelo desenvolvimento? ; (2) como traçar limites entre o aceitável eo inaceitável?

\section{Considerações finais}

As práticas em Saúde Pública, em larga dimensão, têm sido implementadas por meio da relação, permanente e estreita, entrediferentes organismos, diferentes espécies.

A ideia da erradicação ou de controle de doenças por meio da imunização em massa, com a inoculação ea disseminação demicroorganismos, ou pelo controle (extermínio) de um vetor, por exemplo, são algumas das formas clássicas dessa estratégia, dessa prática social. A Saúde Pública sabe que manipula os viventes por meio de ações contínuas em que espécies são dizimadas, entrincheiradas, disseminadas e recriadas. A Saúde Pública sabe, ainda, que essa atuação ocorre não apenas no ambiente, mas também nos corpos dos indivíduos. As práticas de imunização (que vão 
da prospecção dos objetos da natureza aos laboratórios, chegando àsU BS) constituem um exemplo esclarecedor da manipulação de organismos em quehá interações provocadas entre vírus, bactérias e seres humanos, e entre populações diferentes; relação, esta, sempre mediada por um coletivo, porque campanhas de vacinação são, em sua essência, intervenções massivas em comunidades, espécies, populações. N esse sentido, a Saúde Pública tem por objeto - conceitual e prático/ político - "biológicos culturais" diversos; objetos vivos - organismos, espécies, populações -, que ganham concretude nos corpos individuais.

A materialidade dos corpos designa, no entanto, uma finitude, uma localização inseparável no tempo e no espaço, na história e na cultura ${ }^{30}$. Se o corpo humano é finito, a manipulação dos seres vivos, no campo da Saúde Pública, entra, no contexto da sociedade de risco, em colisão com essa materialidade dos corpos, das populações-alvo dessas ações.

Esses processos geram contradições intrínsecas. Segundo Lewontin ${ }^{31}$, há, em larga medida, uma contradição (não oposição) entre indivíduos e sociedade, organismos e espécies. 0 resultado de determinado processo ou fenômeno biológico-social numa determinada população não corresponde, ou até mesmo pode negar, o resultado obtido num indivíduo, evice-versa. Eleexemplifica com a capacidade humana de voar. Indivíduos não voam apenas com suas pernas e braços. Essa é uma limitação biológica individual. $M$ as os homens voam como consequência da ação social. A capacidade de voar é, portanto, um resultado social; mas não éa sociedade que voa, e sim, os seus indivíduos. Essa dialética, do singular edo plural - clássica nasciências sociais-, pode ser incorporada à biologia com a reflexão de Lewontin; eéextremamenteadequada para refletir sobre o processo saúde doença e as intervenções epidemiológicasquea Saúde Pública pratica. 0 resultado de determinado processo ou fenômeno biológico-social num determinado coletivo, numa determinada população, não corresponde ou, até mesmo (estabelecendo uma analogia ao pensamento de Lewontin), nega o resultado obtido num indivíduo, num organismo humano, evice-versa. Não são apenas diferentes níveis de vida que se inter-relacionam, são qualidades diferenciadas de processos, fenômenos e dinâmicas vitais que se estabelecem ao se manipular indivíduos/organismos ecoletivos/populações.

Castellanos ${ }^{32}$, discutindo o modelo de estudo ecológico em epidemiologia, confirma, no quese refere ao processo saúde-doença, a contradição parte todo queLewontin aponta na dinâmica dos fenômenos biológicos em geral. Referindo-se ao trabal ho de Koopman e Longini ${ }^{33}$ sobre as doenças infecciosas, Castellanos observa que os resultados, em termos de doença, em cada indivíduo não dependiam da ação causal sobre a interação dos indivíduos com o grupo [...]. Estes autores destacam que 0 efeito das causas sobre um indivíduo modifica a forma como ele interage com os outros, e, portanto, o efei to das causas sobre eles; a infecção tem uma dinâmica não-linear nas populações ${ }^{32}$.

Acrescente-se a isso que, hoje, sabe-se que variações muito tênues podem engendrar consequências muito diferentes. Um dos principais problemas no campo da biologia, atualmente, é o fato dela trabal har com variáveis que, em grande parte, são impossíveis, na prática, demedir os valores ${ }^{34}$. Isto faz com quetênues variações, produzidas nos seres vivos ou nas populações, sejam, muitas vezes, inviáveis de serem diagnosticadas/verificadas, ainda que venham a constituir fator significativo de futuras alterações, condicionando ou determinando o desenvolvimento ea evolução das espécies. Nesse sentido, pode-se questionar o quanto as práticas em Saúde Pública têm provocado tênues variações nos organismos vivos, nas espécies e nas sociedades, e 0 quanto, e como, essas tênues variações vêm provocando alterações significativas nos seres vivos e no meio. Pressupor, portanto, que a Saúde Pública desencadeia e interfere em processos dessa natureza não é uma hipótese infundada.

A SaúdePública/Coletiva é, reafirmamos, um vasto complexo de pesquisa e de produção biotecnológica. E, nesse sentido, um vasto complexo produtivo de híbridos e riscos.

Berliguer, discutindo seu conceito de doenças antropógenas no contexto da evolução da demanda sanitária, diz que "O ponto central é que precisamos adequar nossa estratégia sanitária a tais mudanças" ${ }^{2}$. Não se pode resolver problemas de Saúde Pública com a simples expansão deorganização, demétodos, deintervenções, que foram criados para combater outros tipos de doenças. "As instituições sanitárias têm que ser funcionais, perante os novos objetivos"2.

A sociedadede risco ehíbridos, em que grande parte do que contribui para a comodidade de determinados grupos ou sociedades inteiras tem consequências negativas a médio ou longo prazo, é cheia de paradoxos. Quem sabe o sonho humano que resultou no "controle" sobre a natureza não possa redefinir novos rumos para a vida? Quem sabe a razão não poderá resolver essa ambiguidade humana? ${ }^{35}$ 
N esse sentido, cabe à própria Saúde Pública/ Coletivaredefinir seus objetos, ereinstituir o pacto sanitário, que deveestar orientado por uma política consistente de biodiversidade e biossegurança.

A Saúde Pública, através de práticas biotecnológicas, vem, por longo período e crescentemente, colonizando a natureza. Transformando, alterando, criando e exterminando organismos eespécies, populações, seja pela substituição pau- latina, seja pela coexistência associativa. Há que dessacralizar essas práticas, dissolver esses conceitos, para que se torne possível sua crítica e superação. A formação social tecnicista, planetária e total itária, que anuncia, nos dias de hoje, "o advento de uma humanidade pós-biológica não expressa o 'fim da humanidade' mas o retorno a seu 'problema real', quenunca foi biológico" ${ }^{36}$. E esse poder solitário merece toda atenção.

\section{Referências}

1. Barreto ML. Emergência, e "Permanescência" das D oenças Infecciosas. M édicos 1998;1(3):19-24.

2. Berlinguer G. M edicina e Política. $1^{\text {a }}$ ed. São Paulo: Hucitec; 1978.

3. Grmek M. O enigma do aparecimento da AIDS. Estudos Avançados 1995; 9(24):229-238.

4. Forattini OP. O pensamento epidemiológico evolutivo: sobre as infecções. Rev. Saude Publica 2002; 36(3):257-262.

5. Buss PM. Globalization and disease: in an unequal world, unequal health! Cad Saude Publica 2002; 18(6):1783-1788.

6. Ujvari SC. A História e suas Epidemias - a Convivência do Homem com os Microorganismos. $1^{\text {a }}$ ed. Rio de Janeiro: SENAC Rio Editora;São Paulo:SENAC São Paulo Editora; 2003.

7. Possas CA. Social ecosystem health: confronting the complexity and emergence of infectious diseases. Cad Saude Publica 2001; 17(1):31-41.

8. Leon P. Sendas de la biotecnologia. In: Zamora A, compilador. Tecnologia: el outro laberinto. $1^{\text {a }}$ ed. Costa Rica: Libro Universitário Regional; 2004. p.171-182.

9. Jacobs-Lorena M. Superbactéria como antibióticos. Folha de São Paulo 2008; 4 abr. p. A24.

10. Mosquito transgênico decola em 10 anos. Folha de São Paulo 2007; 4 abr. p. A 16.

11. Rapidez, não barreiras pode conter epidemias. 0 Estado de São Paulo 2007; 7 jan. p. A21.

12. Garret L. A próxima peste. $1^{\mathrm{a}}$ ed. Rio de Janeiro: Nova Fronteira; 1995.

13. Maldonado J, Gadelha CAG. A política de inovação no contexto da $3^{a}$ revolução tecnológica: conceitos e subsídios para uma reflexão sobre a indústria de vacinas. In: Azevedo N, Gadelha CAG, Ponte CF, Trindade C, Hamilton W, organizadores. Inovação em Saúde. Dilemas e desafios de uma instituição pública. $1^{\text {a }}$ ed. Rio de Janeiro: Fiocruz; 2007. p. 333-346.
14. Latour B. Jamais fomos modernos. Ensaio de antropologia simétrica. $1^{\text {a }}$ ed. Rio de Janeiro: Editora 34; 1994.

15. Brasil. M inistério da Saúde. Secretaria de Vigilância em Saúde. Departamento de Vigilância Epidemiológica. Coordenação Geral do Programa Nacional de Imunização. Campanha Nacional de Vacinação contra a Poliomielite [documento na Internet]. 2007 [acessado 2008 abr 7] [ 21p.]. Disponível em: http://www.saude.gov.br/portal.saude.gov.br/ saude informe_polio2_2007[1]pdf

16. Thomas K. 0 homem e o mundo natural. $3^{\text {a }}$ reimp. São Paulo: Companhia das Letras; 1996.

17. Moscovici S. Essai sur L'Histoire Humaine de La Nature. $1^{\text {ére }}$ ed. Paris: Flammarion; 1977.

18. Rabinow P. Artificiality and enlightenment: from sociobiology to biosociality. In: Rary C, Kwinter S, editors. Incorporations. New York: Zone Books; 1992. p. 234-252.

19. Comissão Gulbenkian para a Reestruturação das Ciências Sociais. Para Abrir as Ciências Sociais. $1^{\text {a }}$ ed. São Paulo: Cortez Editora; 1996.

20. Duclos D. La Nature: principale contradiction culturelle du capitalisme? In: Actuel M arx 1992; 12:4158.

21. Friedman G. 7 Estudos sobre o Homem e a Técnica. $1^{\text {a }}$ ed. São Paulo: Difusão Européia do Livro; 1968.

22. Beck U. A reinvenção da política: rumo a uma teoria da modernização reflexiva. In: Giddens A, Beck $U$, Lash S, organizadores. M odernização reflexiva: política, tradição e estética na ordem social moderna. 2a reimp. São Paulo: Editora UNESP; 1995. p. 11-71.

23. Illich I. A expropriação da saúde. Nêmesis da medicina. $3^{\text {a }}$ ed. Rio de Janeiro: Nova Fronteira; 1975.

24. Beck U. La sociedad del riesgo. Hacia una nueva modernidad. $1^{\text {a }}$ ed. Barcelona-Buenos Aires-M éxico: Paidós; 1998. 
25. Luhmann N. Sociología del riesgo. $1^{a}$ ed. México: Universidad Iberoamericana/Triana Editora; 1998.

26. Adam B, van Loon J. Introduction: repositioning risk; the challenge for social theory. In: Adam B, Beck U, van Loon J, editors. The risk society and beyond. Critical issues for social theory. LondonThousand Oaks-N ew Delhi: Sage Publications; 2000.

27. Ayres JRCM. Sobre o risco. Para compreender a epidemiologia. $1^{\text {a }}$ ed. São Paulo: Hucitec; 1997.

28. Luiz OC, Cohn A. Sociedade de risco e risco epidemiológico. Cad Saude Publica 2006; 22(11):2339-2348.

29. Beck U. La sociedad del riego global. $1^{\text {a }}$ ed. Madrid: Siglo Veintiuno de España Editores; 2002.

30. Ortega F. Corporeidade e biotecnologias: uma crítica fenomenológica da construção do corpo pelo construtivismo e pela tecnobiomedicina. Cien Saude Colet 2007; 12(2):381-388.

31. Lewontin RC. Biology as Ideology. The Doctrine of DNA. New York: Harper Collins Publishers; 1991.

32. Castellanos PL. O Ecológico na Epidemiologia. In: Almeida Filho N, Barreto ML, Veras RP, Barata RB, organizadores. Teoria epidemiológica hoje: fundamentos, interfaces, e tendências. $1^{\text {a }}$ ed. Rio de Janeiro: Fiocruz/Abrasco; 1997. p. 129-147.

33. Koopman J, Longini I. The ecological effects of individual and nonlinear disease dynamics in populations. Am J Public Health 1994; 84: 836-842.

34. Blanc M. Os herdeiros de Darwin. $1^{\text {a }}$ ed. Lisboa: Editorial Teorema; 1991.

35. Zamora A. Entre cosas artificiales. In: Zamora A, compilador. Tecnologia: el outro laberinto. $1^{\mathrm{a}}$ ed. Costa Rica: Libro Universitário Regional; 2004. p. 19-25.

36. Santos LG dos. Politizar as novas tecnologias. 0 impacto sócio-técnico da informação digital e genética. $1^{\text {a }}$ ed. São Paulo: Editora 34; 2003.

Artigo apresentado em 16/06/2008

Aprovado em 10/11/2008

Versão final apresentada em 12/11/2008 